\title{
AS INTERFACES LITERÁRIAS DA GEOGRAFIA: ESPAÇO E INTERDISCIPLINARIDADE NA FORMAÇÃO DO CONHECIMENTO GEOGRÁFICO NA EDUCAÇÃO BÁSICA
}

The literary interfaces of geography: space and didactics in the formation of the geographical knowledge of basic education

Les interfaces littéraires de la géographie: espace et éducation dans la formation des connaissances géographiques dans l'éducation basique

\author{
Júlia Dall'Agnese* \\ Laura Bueno* \\ Aline de Lima Rodrigues** \\ * Graduanda do Curso de Geografia (IGEO/UFRGS) \\ E-mail: dallagnesejuliaa@gmail.com \\ ** Graduanda do curso de Geografia (IGEO/UFRGS) \\ E-mail: buenoclaura@gmail.com \\ *** Doutorado em Geografia pela Universidade Estadual Paulista (UNESP) \\ E-mail: ali_geo1@yahoo.com.br
}

\section{Resumo:}

O presente artigo, que é resultado de pesquisa de iniciação científica, busca analisar a relação que a geografia pode estabelecer com a literatura, através da observação e construção de espaços no imaginário literário. Para isso, apresenta-se uma proposta metodológica que pode ser desenvolvida em sala de aula, com o livro Pra Lá de Marrakesh, de Tiago de Melo Andrade. O livro aborda questões acerca do Continente Africano, permitindo o debate sobre estereótipos de paisagens e sociedades dentro da sala de aula. Desta forma, a Literatura e geografia, dentro de suas singularidades estéticas e epistemológicas, propõem construir narrativas sobre os espaços geográficos.

Palavras-chaves: Ensino de geografia. Literatura. Interdisciplinaridade.

\begin{abstract}
:
The present article aims to analyze the correlation that geography can have with literature, through the observation and the construction of spaces in the literary imaginary. Its purpose is to present an example of a project to be worked at the classroom environment, with the book Pra Lá de Marrakesh, from Tiago de Melo Andrade. The book covers aspects of the African continent, allowing the debate over landscape-related and societal stereotypes in the classroom space. Literature and geography, through their aesthetic and epistemological singularities, aims to construct narratives about the geographical spaces.
\end{abstract}

Key-words: Geography teaching. Literature. Interdisciplinarity. 


\begin{abstract}
Résumé:
Le présent article cherche à analyser la relation que la géographie peut établir avec la littérature, à partir de l'observation et de la construction d'espaces dans l'imaginaire littéraire. La proposition est de présenter un exemple de projet à travailler en classe, avec le livre Pra Lá de Marrakesh, de Tiago de Melo Andrade. Le livre aborde des questions sur le continent africain, permettant un débat sur les stéréotypes des paysages et des sociétés pendant les cours. La littérature et la géographie, dans leurs singularités esthétiques et épistémologiques, proposent de construire des récits sur les espaces géographiques.
\end{abstract}

Mots-clés: Enseignement de la géographie. Littérature. Interdisciplinarité.

\title{
1. Introdução
}

A Geografia existe como uma ciência que busca compreender as dinâmicas que ocorrem na superfície terrestre por meio da análise das ocorrências de fenômenos naturais e sociais, que não podem ser analisados isoladamente. Como Costella aponta em sua tese, "o significado da construção do conhecimento geográfico é gerado por vivências e por representações espaciais(...) a geografia é a ciência que promove a construção e a interpretação dos nós que compõem uma rede de eventos espaciais" (COSTELLA, 2008, p. 55). Logo, o encontro dos fatores naturais e antrópicos formam um elo que nos permite a constante formação do espaço geográfico. O desenvolvimento técnico e tecnológico das sociedades permitiu o aumento do domínio do ser humano sobre a natureza, de forma que a rede espacial se torna cada vez maior e densa. A utilização de técnicas e tecnologias nas áreas de comunicação e transporte, que se encontra no período histórico mais avançado, é o que permite que os eventos da superfície terrestre sejam muito mais complexos e conectados. Infelizmente, percebemos no espaço global que o acesso às técnicas e tecnologias não ocorre de maneira democratizada. Partindo desse pressuposto, a difusão dos objetos técnicos não se dá de forma homogênea, e sim de forma desigual, assim como eles se manifestam na história e no território. Cada sociedade se monta, através das técnicas, em momentos diferentes (SANTOS, 2017). A compreensão do espaço-tempo condiciona ao longo do globo, inúmeros aspectos da vida social desigual, como por exemplo, relações de trabalho, acesso à educação e aspectos culturais.

O estudo do espaço geográfico nos permite compreender as diferentes percepções, configurações e até contradições de diversas sociedades. Todavia, pode se utilizar novamente das reflexões feitas por Milton Santos (2017) que descreve o espaço geográfico como um híbrido, onde a definição social é de suma importância, assim como as técnicas. Por exemplo, nas estruturas físicas de algumas cidades podemos reconhecer relevos adequados para construções de moradias, e em outras não. O conhecimento acerca do relevo e dos espaços da cidade nos permitem questionar o porquê existem pessoas construindo e morando em habitações que não estão em áreas seguras, apesar destas estarem reconhecidas como tal. É devido a essas reflexões, que relacionam-se de maneira dialética com informações e saberes, que o estudo da geografia se faz necessário em sala aula, pois apropria o aluno do espaço que o rodeia, por meio de percepções, questionamentos e pela possibilidade de intervenção.

ParaOnde!?, Porto Alegre, v.14, n.1, p.127-142, 2020.http://seer.ufrgs.br/paraonde 
A partir dessa perspectiva, o presente artigo busca analisar a interação entre a geografia e a literatura brasileira no ensino de geografia, a partir do livro "Pra lá de Marrakesh, Rita Pancada na África", de Tiago de Melo Andrade, publicado em 2016, com uma proposta didático-metodológica para ser realizada pelos professores, no que diz respeito ao ensino de questões étnicas e raciais. A história do livro narra as aventuras da menina Rita, moradora da cidade de Formiga em Minas Gerais, que com sua personalidade curiosa e estabanada, acaba indo parar na Floresta do Congo no continente Africano. Em suas tentativas de voltar para casa, a protagonista acaba conhecendo vários países e seus diferentes modelos e organizações de sociedade, por onde transita em meio a diferentes paisagens, fazendo tanto amigos quanto inimigos.

Este artigo é resultado de um projeto de pesquisa que procurou desenvolver propostas metodológicas entre literatura e geografia voltadas para a educação básica, no qual se pesquisou 10 obras literárias, incluindo a obra "Pra Lá de Marrakesh".

A metodologia utilizada para a elaboração da proposta didáticometodológica se deu em duas etapas. Primeiramente, realizou-se a leitura detalhada da obra, para observar os temas geográficos e transversais que a narrativa apresenta, criando uma breve sinopse sobre o livro. Posteriormente, elaborou-se a proposta metodológica, que foi o espaço onde projetou-se a atividade a ser realizada na sala de aula detalhadamente, esta proposta contém: unidade temática e ano indicado; objetivos de aprendizagem; habilidade e competência; tema de proposta; apresentação de tema; contextualização; problematização; ação propositiva e sugestões sobre o tema, baseado em Costella (2012).

A partir disso, a unidade temática foi retirada da Base Nacional Comum Curricular (BNCC, 2017), juntamente com o ano indicado. Os objetivos foram pensados para contemplar as habilidades e competências que constam na BNCC para as áreas do ensino de geografia e do ensino das ciências humanas. O tema da proposta é o título dado ao projeto proposto, como uma forma de apresentar a proposta para o docente que estiver lendo este trabalho. A apresentação do tema é um resumo sobre o livro, apresentando personagens e o espaço temporal onde se passa a história. A contextualização é uma introdução ao tema geográfico principal abordado pelo livro, para o professor inteirar-se sobre o assunto e relacioná-lo aos conteúdos trabalhados. Já a problematização, são os questionamentos que os professores podem promover em sala de aula para introduzir a proposta, sendo reflexões primárias sobre a temática para instigar os alunos. Geralmente, as problematizações apresentam contradições da nossa sociedade. O desenvolvimento do tema refere-se as atividades propostas para o professor realizar após a leitura do livro com os alunos, como por exemplo, trabalhos de pesquisa, atividades em grupo e criação de projetos. Por fim, as sugestões sobre o tema são ideias para o docente, um referencial sobre a temática geográfica do livro.

O livro foi escolhido devido a necessidade de se discutir sobre a temática do Continente Africano e suas paisagens e contextos sociais e culturais, e também, abordar questões étnicos raciais nos espaços escolares. Pensando no contexto social do Brasil, propor mudanças que auxiliem na desconstrução dos estereótipos sobre o continente africano e sobre a temática racial nas escolas é

ParaOnde!?, Porto Alegre, v.14, n.1, p.127-142, 2020.http://seer.ufrgs.br/paraonde 
uma forma de participar da construção de uma sociedade igualitária, sem preconceitos. Nesse sentido, ressalta-se a importância da interação entre geografia e a literatura brasileira nos anos finais do Ensino Fundamental.

\title{
2. Geografia e Literatura: prática interdisciplinar nos espaços escolares
}

O processo educacional e o ambiente escolar possuem desafios enraizados que vão desde a construção do currículo, das propostas pedagógicas utilizadas, até o recorrente movimento de sucateamento da escola pública no Brasil. Pesquisar, discutir e colocar em ação práticas reflexivas, como o uso da interdisciplinaridade a partir da literatura, pode ser instigante para os alunos desde a educação básica até a universidade. Assim, é possível estabelecer uma conexão fundamentada dos conteúdos para os alunos, mostrando que mesmo sendo dividido em disciplinas, os conteúdos são conexos, necessitando uns dos outros, para uma melhor compreensão.

A literatura, em especial, será tratada neste artigo como instrumento pedagógico de ensino de geografia. Sendo da curiosidade do geógrafo conhecer o espaço em que vive e (re)pensar intervenções, a literatura pode ser um importante meio para aprender de uma forma lúdica e reflexiva. Antônio Candido (2011, p. 177) em O direito a leitura aponta a importância da leitura:

\begin{abstract}
Por isso é que nas nossas sociedades a literatura tem sido um instrumento poderoso de instrução e educação, entrando nos currículos, sendo proposta a cada um como equipamento intelectual e afetivo. Os valores que a sociedade preconiza, ou os que considera prejudiciais, estão presentes nas diversas manifestações da ficção, da poesia e da ação dramática. A literatura confirma e nega, propõe e denuncia, apoia e combate, fornecendo a possibilidade de vivermos dialeticamente os problemas.
\end{abstract}

À vista disso, é através da espacialidade e da percepção de tempo possibilitada pelos livros, que conseguimos observar dinâmicas sociais, políticas e ambientais distintas. Cada livro retrata também a época onde foi escrito, marcando um período do tempo.

A partir da percepção dos ambientes retratados nos livros, principalmente de como é feita a descrição do espaço e do tempo, a geograficidade pode ser facilmente percebida pela Geografia Humana, umas das vertentes da Geografia que trabalha os campos sociais. Cabe aqui ressaltar um adendo que pode ser esclarecido segundo Moraes (2014, p. 34), em seu artigo Geografia, Interdisciplinaridade e metodologia, no qual nos diz que não podemos considerar toda reflexão sobre o espaço um campo geográfico totalizado:

\footnotetext{
Abandonado a soberba de tomar como "geografia" qualquer reflexão sobre o espaço ou a superfície da Terra, fica evidente que tal campo disciplinar cobre um tipo específico de discurso no universo que está sendo chamado de "pensamento geográfico". A produção da geografia acadêmica é tomada então como uma modalidade de discurso, com uma história e tradição própria, passível de ser analisada com especificidade como qualquer outro discurso do amplo universo considerado. Nesse sentido, o conhecimento disciplinar aparece como tema do campo de investigação da geografia cultural, isto é, como objeto de ser interesse analítico.
}

ParaOnde!?, Porto Alegre, v.14, n.1, p.127-142, 2020.http://seer.ufrgs.br/paraonde 
Partindo desse pressuposto, a aproximação dos estudos geográficos aos literários é concebida através dos estudos humanistas, e com a chamada Geografia Cultural. A Geografia Cultural começou a se desenvolver no Brasil a partir dos anos 1990 (CLAVAL, 2013, p. 2). Com a modernização e a descoberta da diversidade regional do país, essa vertente da geografia repercutiu no cenário geográfico nacional, e auxiliou em uma análise da unidade brasileira. O interesse pela interação entre geografia e literatura vai ao encontro da Geografia Cultural, já que auxilia na representação dos espaços e lugares.

Utilizando a reflexão de Paulo Freire (1996, p. 25), em seu livro Pedagogia da Autonomia: "ensinar não é transferir conhecimento, mas criar as possibilidades para a sua produção ou a sua construção" (grifo nosso), a literatura se apresenta como possibilidade, pois de uma maneira lúdica posiciona o aluno como agente de observação e interpretação do espaço, desvestindo-se do racionalismo científico. A fim de contribuir para a formação cidadã do aluno, a leitura possibilita ir ao encontro dos espaços ausentes, espaços distantes da realidade do aluno é fundamental.

Assim, para que o ensino de geografia tenha relevância para o aluno, é necessário ir além do próprio conteúdo. Segundo Costella (2012, p. 37) em seu livro A Geografia em Projetos Curriculares: Ler o Lugar e Compreender o Mundo, "educar é complementar o conteúdo de ações e reações que o torne significativo", ou seja, podemos estabelecer conexões com as outras disciplinas para fomentar o conhecimento dos alunos, trabalhando a interdisciplinaridade. Por exemplo, em uma aula sobre movimentos de translação cabe complementar a explicação utilizando-se da teoria física das Leis de Kepler, que explicam o motivo do Sol ocupar um dos focos da elipse. É justamente a relação da geografia com outros conteúdos e saberes que a torna mais concreta aos olhos do aluno.

O que seria da geografia sem a biologia para contextualizar as paisagens compostas por flora, que se repetem nas zonas climáticas por motivos de adaptação com o meio? Sem a história, que em suas narrativas nos permite entender a construção dos territórios? Sem a física, que nos dá a base para conhecer a constituição da atmosfera, nos permitindo refletir, por exemplo, sobre modos de produção que afetam essa constituição e que prejudicam a vida humana? Essas relações ocorrem em todos os conteúdos e em vários sentidos, de um para o outro. Além disso, a geografia transcende os conteúdos do ambiente escolar, e se encontra com saberes que não se conceituam diretamente como científico. Encontramos geografia nos filmes, nas música, nas artes, nas literaturas, na família, na subjetividade e entre tantos outros espaços. À vista disso, Olga Pombo (2008, p.22) cita em seu artigo Epistemologia da Interdisciplinaridade, o conceito de fecundação recíproca das disciplinas, exemplificando-o como:

Sabemos como grande parte da Química que hoje conhecemos seria impossível sem a Física Quântica, como os dispositivos matemáticos de Rieman foram decisivos para a Física da Relatividade, como a Biologia de Darwin é devedora da economia concorrencial de Smith e Malthus. É nesse sentido que, por exemplo, aquilo a que vulgarmente se chama "invenção pelo acaso" seria afinal resultante da irrupção súbita, na consciência do praticante de uma determinada disciplina, de uma possibilidade explicativa utilizada por uma outra disciplina que fez

ParaOnde!?, Porto Alegre, v.14, n.1, p.127-142, 2020.http://seer.ufrgs.br/paraonde 
parte da sua formação de base, que estava lá, latente desde esse momento.

Para o aluno, o uso da interdisciplinaridade pode ser uma chance de tornar mais concreto os conteúdos que aprende. Costella (2012, p.46), "para ser capaz de interpretar a sociedade contemporânea, a partir do trabalho na escola, é necessário formar o aluno para um pensar interdisciplinar, que busque estabelecer relações entre os elementos que compõem seu ambiente". Não somente como aliados do processo pedagógico, devemos lembrar que os outros conteúdos, como por exemplo de biologia, de química, de física, por si só podem ser agentes de construção do espaço geográfico, e por isso, muitas vezes também sustentam os conteúdos de geografia.

A literatura permite ao geógrafo experienciar um cenário descritivo do espaço, onde a imaginação propicia uma "viagem" pela espacialidade e pela geograficidade. Além de um fator meramente descritivo, a literatura narra lugares e personagens que nele vivem, sendo carregada de simbolismo e subjetividades que são importantes para análise do espaço, pois, para além dos termos científicos que nos classificam como seres antrópicos, nós, seres humanos, somos movidos pelas nossas passionalidades que constroem o espaço também. O livro Vidas Secas, de Graciliano Ramos (2003), é exemplo da geograficidade. O primeiro capítulo começa com a seguinte narrativa Na planície avermelhada os juazeiros alargavam duas manchas
verdes. Os infelizes tinham caminhado o dia inteiro, estavam cansados
e famintos. Ordinariamente andavam pouco, mas como haviam
repousado bastante na areia do rio seco, a viagem progredira bem três
léguas. Fazia horas que procuravam uma sombra. A folhagem dos
juazeiros apareceu longe, através dos galhos pelados da caatinga rala.
(RAMOS, 2003. p. 2)

O trecho descreve uma paisagem do sertão, suas temperaturas elevadas relacionadas ao tom de vermelho, o ambiente seco devido aos baixos índices pluviométricos e a vegetação adaptada ao meio. Ademais, além da interpretação geográfica, também atribui significado para um corpo humano: o que significa ser e estar nesse lugar, como procurar uma sombra em um horizonte seco e sem vegetação, de que modo a narrativa cria um cansaço físico e psicológico. $\mathrm{Na}$ sequência, o texto de Graciliano Ramos (2003) também significa o que a localização implica na relação da família, em que o pai tem que ser firme e garantir que nenhum membro seja deixado para trás:

\footnotetext{
Os juazeiros aproximaram-se, recuaram, sumiram-se. O menino mais velho pôs-se a chorar, sentou-se no chão. - Anda, condenado do diabo, gritou-lhe o pai. Não obtendo resultado, fustigou-o com a bainha da faca de ponta. Mas o pequeno esperneou acuado, depois sossegou, deitou-se, fechou os olhos. Fabiano ainda the deu algumas pancadas e esperou que ele se levantasse. (RAMOS, 2003. p.3)
}

No fim, o pai tem que passar por cima do próprio cansaço e carregar o filho nas costas para que todos possam atravessar a paisagem que segue no horizonte. O início do livro nos apresenta de maneira sensível como a geografia não se trata apenas de uma análise da superfície. Além do espaço que estudamos, devemos ter olhos para os sujeitos que por ele caminham, como

ParaOnde!?, Porto Alegre, v.14, n.1, p.127-142, 2020.http://seer.ufrgs.br/paraonde 
constroem e são construídos por esse espaço, como são formadas suas relações sociais e como interagem. Por mais que se apresente aos alunos o espaço geográfico, podemos lapidar as possibilidades de reflexões que esse aluno possa vir a ter. Para reconhecer, compreender e propor modificações no ambiente, o aluno precisa de autonomia e senso crítico, e isso pode vir da sua produção de conhecimento individual, processo intelectual que pode ser ofertada através da leitura, por exemplo.

Partindo desse pressuposto, os escritos de Frederico Roza Barcellos (2009, p.41), em seu artigo Espaço, Lugar e Literatura: o olhar geográfico machadiano sobre a cidade do Rio de Janeiro, descrevem que "na relação entre Geografia e Literatura, os textos literários apresentam-se como um rico material a serem apreciados pelos geógrafos, pois eles evocam a alma dos lugares e o cotidiano das pessoas". A literatura, a música, a arte podem se interligar com a geografia, pois auxiliam no objetivo da disciplina em permitir que o sujeito crie relações com os diversos objetos que compõem o planeta Terra. Sendo assim, a literatura é uma forma de representação da realidade, por vezes se estabelecendo de forma ficcional, mas sempre necessitando de um espaço/tempo para existir. Vista deste modo a literatura aparece clara, como uma manifestação universal de todos os homens em todos os tempos. Não há povo e não há homem que possa viver sem ela (CANDIDO, 2011). A construção de obras literárias por diferentes povos e em diferentes tempos, possibilita o uso de diversas formas e gêneros de literatura que podem ser levadas para sala de aula, como poemas, contos, romances e novelas.

Ressalta-se aqui que independente da narrativa escolhida, o papel do professor é fundamental para reconhecer se a leitura se apresenta adequada e coerente para os alunos com quem trabalha. Essa história, por sua vez, se materializa em um espaço - e é a partir disso que a geografia começa a se compor. Milton Santos (2017, p. 100) define o espaço geográfico como o "resultado da conjugação entre sistemas de objetos e sistemas de ações, permite transitar do passado ao futuro, mediante a consideração do presente". Esse espaço é composto por objetos que existem na superfície do planeta, que são "herança da história natural e todo resultado da ação humana que se objetivou" (SANTOS, 2017, p. 72). Então, para estabelecer esse diálogo com o espaço, e para aproximar-se da realidade do aluno, a literatura pode ser utilizada, visto que a partir de uma avaliação do professor sobre a turma com quem trabalha, é possível selecionar uma obra literária que contemple os conteúdos geográficos e apresente em sua narrativa questões de afinidade para os alunos.

A partir disso, vinculamos a literatura ao ensino da geografia como uma ferramenta de auxílio para a construção do conhecimento do aluno. Como professores, cria-se um ambiente de possibilidades onde o aluno pode indagar sobre a formação do mundo, seja ela física ou social. A literatura pode ser utilizada como instrumento de linguagem pedagógica para estabelecer pontos de contato entre os conteúdos escolares. No que tange à literatura, em um romance, o escritor estabelece relações entre as diversas partes de um objeto, descreve, assinala as similitudes, marcando os contrastes e as proporções que existem naquele espaço.

Assim, as descrições possibilitam observar como configuram-se os lugares, e como são formados através das experiências vivenciadas. Sendo

ParaOnde!?, Porto Alegre, v.14, n.1, p.127-142, 2020.http://seer.ufrgs.br/paraonde 
assim, o lugar é parte essencial de nossa identidade, enquanto sujeitos. Segundo Amélia Regina Batista Nogueira (2001, p. 45,), em sua tese de doutorado intitulada Percepção e Representação Gráfica: A "Geograficidade" nos Mapas Mentais dos Comandantes no Amazonas, "os homens de muitos lugares são reconhecidos pelas características que levam deles através dos componentes culturais: hábito alimentar, linguagem, vestimenta, crenças etc. Assim, o lugar circula, migra: as pessoas carregam os lugares consigo". A literatura por sua vez "cria e cimenta identidades locais, regionais e nacionais, impondo-se como representação coletiva que funda práticas e vínculos culturais e sociais" (ARAÚJO apud MARANDOLA JR; OLIVEIRA, 2009, p. 492).

Em seus estudos, Nelson Rego, no livro Saberes e Práticas na Construção de Sujeitos e Espaços Sociais (2006, p. 179) auxilia no entendimento do conceito de geração de ambiências, que é "um conjunto diversificado de experiências inovadoras no ensino de geografia ou em campos de conhecimento afins à geografia", o que nos permite compreender que a literatura poderia ser uma experiência inovadora no ensino de geografia em sala de aula. O universo imaginativo literário nos possibilita observar o espaço além dos conceitos geográficos. O conceito de espaço trabalhado em sala de aula, por vezes é difícil de ser materializado e exemplificado aos alunos. Por se tratar de um conceito que é abstrato, condição de existência dos fenômenos, torna-se mais distante do entendimento deles. Quando os alunos não compreendem

o conteúdo, o motivo pode estar relacionado com o fato de não conseguirem estabelecer relações entre o conteúdo e a sua vida, logo eles não veem significado no que foi estudado.

Pensando a educação como uma experiência antropológica presente em diversas culturas, busca-se compreender as dinâmicas da literatura em simbiose com a geografia, permitindo ao aluno descomplexificar conceitos geográficos, difíceis de serem compreendidos, por ainda estarem envoltos de linguagem científica. Assim, conforme Carlos Rodrigues Brandão (1986, p.18), em seu artigo A Educação como Cultura: Memórias dos Anos Sessenta, "ao transcender um mundo dado pela natureza e ao construir, material e simbolicamente um mundo de cultura, o homem afirma-se, por sua vez, como criador de suas próprias condições de existência e como sujeito da história." O aluno pode produzir as suas narrativas para compor o seu espaço geográfico, e a partir disso compreender questões sociais presentes em seu cotidiano. Todavia, acreditamos que o professor é capaz de compor uma justa medida entre o conhecimento do outro e a linguagem dos alunos. Nesse sentido, o artigo traduzido por Cleonice Puggian para a Revista de Educação, Ciências e Matemática, intitulado "Sobre a teoria da transposição didática: algumas considerações introdutórias", traz o conceito de transposição didática de Yves Chevallard (2013). O autor pode nos auxiliar na compreensão da forma como o conhecimento é ensinado, logo

\footnotetext{
A transição do conhecimento considerado como uma ferramenta a ser posto em prática, para o conhecimento como algo a ser ensinado e aprendido, é precisamente o que eu tenho chamado de transposição didática do conhecimento. (2013, p.9)
}

ParaOnde!?, Porto Alegre, v.14, n.1, p.127-142, 2020.http://seer.ufrgs.br/paraonde 
A literatura em sala de aula é uma maneira de aplicar a abordagem da geografia cultural como proposta pedagógica. A capacidade dos livros de ressaltar a alma dos lugares e o cotidiano das pessoas representa a perspectiva da geografia cultural, que, além da análise de fenômenos, busca a relação entre localização e suas significações.

\section{A desconstrução do estereótipo da paisagem africana através da leitura}

Com base nas reflexões feitas sobre a utilização da literatura no ensino de geografia, apresentaremos uma proposta metodológica comentada. Utilizando o livro "Pra lá de Marrakesh, Rita Pancada na África", do autor Tiago de Melo Andrade, publicado em 2016 (ANDRADE, 2016), como um instrumento didático-pedagógico dentro de sala de aula que permite trabalhar a geografia, possibilitando a reflexão sobre as potencialidades da literatura para expandir o debate além do conteúdo geográfico disciplinar. O livro será utilizado neste artigo como proposta literária para ser trabalhado no $8^{\circ}$ ano do Ensino Fundamental II. A história do livro se passa no tempo atual e começa localizada na cidade de Formiga, em Minas Gerais, onde a protagonista Rita Pancada mora. Rita marca o início da história, ao se aventurar dentro de uma feira de ciências, se colocando em uma viagem para o continente africano por meio de um mini avião, e durante sua tentativa de voltar para casa acaba conhecendo diferentes países do continente. O livro é oportuno para trabalhar a geografia que envolve o continente africano, visto que a história é suporte para abordar a diversidade paisagística e física do continente, contextualizar historicamente o território africano, e também representar de maneira diversa a população com as diferentes culturas que constituem a África.

Buscando uma educação mais igualitária e antirracista, a proposta está vinculada com a Lei 10.639, de 09 de janeiro de 2003, que estabelece as diretrizes e bases da educação nacional, para incluir no currículo oficial das redes de ensino a obrigatoriedade da temática "História e Cultura AfroBrasileira", e dá outras providências. A inserção dessas políticas públicas como auxílio na reparação histórica é essencial para a reconstrução de um espaço igualitário no Brasil, inclusive no campo da educação, que, em um período, ao longo da história impediu pessoas negras de terem acesso à terra, escola e trabalho.

O impacto causado pela exclusão racial está presente na atualidade. No Brasil, as estatísticas confirmam que as pessoas de pele branca estão, na maioria, em uma posição socialmente superior as de pele negra: segundo o PNAD Contínuo de 2016, a taxa de analfabetismo entre pretos é de 9,9\%, e entre brancos essa taxa cai para $4,2 \%$. A percepção limitante sobre o continente africano é consequência do processo colonial brasileiro, assim como a manutenção dessa percepção dentro do ensino escolar, que corrobora para que não ocorram mudanças nas estruturas sociais no país. Sendo assim, os escritos de Miguel Arroyo (2012, p.29) em seu texto Outros Sujeitos, Outras Pedagogias vão de acordo as nossas afirmações

O pensamento pedagógico é levado de um lado a se alargar aos processos pedagógicos mais complexos e mais tensos de nossa história. De outro lado é levado a se enraizar, contextualizar nas suas especificidades dessa história social, política, cultural e também pedagógica.

ParaOnde!?, Porto Alegre, v.14, n.1, p.127-142, 2020.http://seer.ufrgs.br/paraonde 
Desde aproximadamente a metade do século XVI com o fim dos Governos Gerais a nível colonial, homens e mulheres foram trazidos da África sem consentimento para serem escravos nas colônias brasileiras. A abolição da escravatura aconteceu somente em 1888. Todavia, não ocorreram medidas de reparação e reinserção social que possibilitassem aos negros acesso à terra, educação e trabalho; pelo contrário, foram inseridas políticas estatais de branqueamento da sociedade brasileira, como as Leis de Imigração do século XIX. Sobre as políticas e ideologias de branqueamento e seu efeito sobre os sujeitos Lélia Gonzalez (1988, p.73) aponta, em seu texto A categoria políticocultural de amefricanidade, que

\begin{abstract}
Veiculada pelos meios de comunicação de massa e pelos aparelhos ideológicos tradicionais, ela reproduz e perpetua a crença de que as classificações e os valores do Ocidente branco são os únicos verdadeiros universais. Uma vez estabelecido, o mito da superioridade branca demonstra sua eficácia pelos efeitos de estilhaçamento, de fragmentação da identidade racial que ele reproduz: o desejo de embranquecer é internalizado
\end{abstract}

Além disso, em algumas escolas ainda estuda-se uma história centralizada na chegada do homem europeu ao nosso continente, não tratando da pluralidade étnica de culturas e povos. Desta forma, isso sustenta o desejo internalizado da branquitude "com a simultânea negação da própria raça e da própria cultura” (GONZALEZ, 1988, p.73). Entretanto, não podemos traçar uma afirmação como se a historiografia não tivesse se renovado e modificado suas percepções acerca da colonização. Falamos aqui de alguns casos que ainda seguem essa história centralizada no homem branco europeu.

Outra problemática suscitada pelo livro aborda a dimensão latitudinal do continente africano - sendo cortado pelos três principais paralelos: o Trópico de Câncer, o Trópico de Capricórnio e a linha do Equador - e as implicações dessas dimensões na composição de diferentes tipos de biomas, de fauna, de flora dos países e como as populações se relacionam com esses ambientes. Por exemplo, na primeira parada de Rita, na floresta tropical do Congo, que é descrita como uma selva quente. Assim, devido às suas altas temperaturas a população dos Pigmeus optara por se vestir com vestes mais frescas. Como está descrito no livro (p.25): "Entre eles, até por conta do calor que faz na África, não havia muita preocupação com roupas. Homens e mulheres apenas amarravam algum pano, uma tanga, em torno da cintura, ficando com o torso nu".

Em outro momento, quando as amigas se perdem pelo deserto do Saara e enxergam apenas "o dourado da areia e o azul limpo de um céu amplo, sem algodão de nuvens para fazer sombra" e nesta situação conhecem o povo dos Tuaregs, que devido ao ambiente físico utilizam camelos para se locomover, pois "possuem uma pata especial para pisar na fofa e quente areia do deserto" (p.111) e durante as tempestades de areia "servem como uma espécie de parede contra as tempestades" (p.114).

Entretanto, o conhecimento construído no ambiente escolar acerca do continente africano é cheio de estereótipos, muitas vezes percebendo a África como um único espaço, uniformizado, e principalmente subdesenvolvido. A partir disso, sugere-se que o professor reflita com seus alunos sobre os conhecimentos pré-existentes acerca do continente, e as principais impressões que os alunos

ParaOnde!?, Porto Alegre, v.14, n.1, p.127-142, 2020.http://seer.ufrgs.br/paraonde 
têm quando falamos em África. As opiniões dos alunos podem ser anotadas para que seja possível comparar os estereótipos do imaginário com as informações que vão ser construídas durante a atividade prática.

Um dos principais estereótipos é o imaginário de uma África tribal, que tão erroneamente surge no fictício pensamento como um território primitivo. Ao longo da história do continente existiram e existem diversos tipos de sociedades. Há aquelas ausentes de Estado, por exemplo, sociedades familiares que constituíam aldeias ou povos nômades, cujos grupos moviam-se pelo território conforme as condições climáticas e de comércio favoráveis. Exemplos dessas diferentes sociedades são retratados no livro. Os Pigmeus, com quem Rita passa uns dias, formam uma tribo em que a sabedoria e cura são associadas à figura de uma anciã, chamada Tumaini. Já os Tuaregs, aqueles que ela conheceu no deserto, são a representação do povo nômade que "estão sempre mudando, viajando e praticando o comércio em várias partes do deserto" (p.103). São retratadas também sociedades constituídas de Estado, como é o caso Marrakesh, uma cidade de Marrocos por onde Rita passa, e é mencionada no livro como um território que "ao longo dos séculos já esteve sob o controle de diferentes Estados como Espanha, Inglaterra e França” (p.70).

O livro, durante a narrativa da história, apresenta diálogos e situações que permitem ao professor questionar os alunos sobre as relações da África com outros continentes. Quando Rita está em Marrakesh, além de citar a dominação por países europeus, a personagem fica curiosa sobre alguns hábitos culturais, como "Por que as mulheres usam véu?" (p.75). Rita descobre que a maioria dos habitantes da África do norte seguem a religião Islâmica, e que isso influencia na cultura da população, como regras de vestimenta das mulheres, proibição de bebidas alcoólicas, ou regras de etiqueta/sociabilização como "homens não cumprimentam as mulheres com apertos de mão ou beijinho no rosto. Isso é considerado falta de respeito e de educação" (p.76). São diálogos que servem para iniciar a contextualização histórica da África, que além de ser explorada e realizar trocas com o continente europeu, também realizava tais práticas com a Ásia oriental, o que algumas vezes passa despercebido nas salas de aula.

$\mathrm{Na}$ proposta de aula, pensou-se que num primeiro momento, em o professor trabalhar mapas da África com os alunos, abordando aspectos como hidrografia, vegetação, relevo e construindo conhecimentos sobre latitudes. Com esta parte coesa, e tendo a potencialidade de abordar a relação do conceito de latitude com zonas climáticas, pode se utilizar imagens de diferentes paisagens/biomas que servirão como dica para uma dinâmica onde os alunos devem tentar acertar esses lugares no globo. Por exemplo, mostrar uma imagem da floresta do Congo e pedir para que os alunos encontrem a localização no globo, a partir da habilidade de reconhecer que a latitude equatorial apresenta condições climáticas favoráveis para formação de florestas. Para contextualizar a atividade é recomendado que se utilize paisagens que estejam inseridas na história do livro, como por exemplo, o deserto do Saara, a garganta de Olduvai ou a cidade de Marrakesh.

Por conseguinte, propõe-se ao professor criar a "Feira de Países", onde os alunos seriam divididos em grupos de até cinco pessoas e cada grupo escolheria um país da África para representar. Cada grupo ficaria encarregado de apresentar informações sobre o país, como características físicas, dados

ParaOnde!?, Porto Alegre, v.14, n.1, p.127-142, 2020.http://seer.ufrgs.br/paraonde 
populacionais, aspectos culturais, comidas típicas, alguma construção ou processo do país que reflita a sua relação com seu meio natural, como um modo agrícola exclusivo da região, ou uma tecnologia desenvolvida para prevenir danos ambientais que seja de comum uso no país, qual a universidade mais importante do país, filmes produzidos no país nos últimos dez anos, grandes empresas localizadas no país. Os alunos iriam interagir com os colegas, trocando conhecimentos a partir de um envolvimento dialógico em relação ao conteúdo. O papel do aluno aqui é ser pesquisador, mas para isso ele necessita do apoio do professor para guiar os sites para as buscas serem feitas, e indicar materiais de leitura para os grupos, a fim de evitar que mais conhecimentos estereotipados sejam reproduzidos no ambiente escolar.

Para finalizar a proposta de ensino, pensou-se num mapa temático da África construído em conjunto com os alunos. Cada grupo escolheria como quer caracterizar seu país no mapa, com um elemento marcante da cultura. Pensouse também, caso o professor tenha mais que uma turma no mesmo ano, ele pode fazer com que os alunos transitem entre as turmas para conhecer os diversos países da feira. Na tabela abaixo (Quadro 1) está apresentado o fluxograma da proposta metodológica citado anteriormente. O quadro está dividido entre momento de aula, atividade realizada e sugestões de atividades que possam ser trabalhadas pelo professor.

Quaro 1 - Fluxograma da proposta metodológica

\begin{tabular}{|c|c|c|}
\hline Momento & Atividade realizada & Sugestões para atividade \\
\hline $\begin{array}{l}\left.1^{\circ}\right) \text { Apresentação do livro } \\
\text { para a turma }\end{array}$ & $\begin{array}{l}\text { Docente deve escolher } \\
\text { tempo de leitura com alunos } \\
\text { de acordo com a condições } \\
\text { da turma }\end{array}$ & $\begin{array}{l}\text { - Leitura em grupo } \\
\text { - Leitura individual }\end{array}$ \\
\hline $\left.2^{\circ}\right)$ Trabalho com mapas & $\begin{array}{l}\text { Apresentar o continente } \\
\text { africano a partir de mapas de } \\
\text { geografia física }\end{array}$ & $\begin{array}{l}\text { - Hidrografia } \\
\text { - Vegetação } \\
\text { - Relevo } \\
\text { - Clima }\end{array}$ \\
\hline 3ㅇ) Atividade com globo & $\begin{array}{l}\text { Apresentar para os alunos } \\
\text { diferentes paisagens da } \\
\text { África e pedir para que eles } \\
\text { localizem no globo. É } \\
\text { interessante } \\
\text { paisagens que são citadas } \\
\text { no livro }\end{array}$ & $\begin{array}{l}\text { - Floresta do Congo } \\
\text { - Deserto do saara } \\
\text { - } \text { Cidade de } \\
\text { - Garrakech } \\
\text { - Garganta do Olduvai }\end{array}$ \\
\hline $\begin{array}{l}\left.4^{\circ}\right) \text { Construção de uma feira } \\
\text { de países }\end{array}$ & $\begin{array}{l}\text { Dividir a turma em grupos } \\
\text { para representar países do } \\
\text { continente. Cada grupo } \\
\text { ficaria encarregado de } \\
\text { apresentar uma banca de } \\
\text { informações sobre o país }\end{array}$ & $\begin{array}{l}\text { - Aspectos sociais } \\
\text { - Aspectos } \\
\text { - } \text { Aspulacionais } \\
\text { - Aspectos físicas } \\
\text { - Aspectos culturais }\end{array}$ \\
\hline
\end{tabular}

Fonte: Relatório de Pesquisa (2020)

ParaOnde!?, Porto Alegre, v.14, n.1, p.127-142, 2020.http://seer.ufrgs.br/paraonde 
Um livro pode apresentar inúmeras potencialidades para trabalhar um conteúdo de geografia. Entretanto, a literatura não tem o ofício de ser um material didático e nem de contemplar todos os aspectos da temática que possui em seu enredo, por exemplo, o livro "Vidas Secas" não é uma enciclopédia sobre o sertão nordestino. É necessário que o professor, ao escolher um livro para trabalhar com os alunos, tenha em mente seus limites para com o conteúdo geográfico e busque outros meios para contemplar pontos que durante a narrativa não foram abordados e/ou aprofundar outros.

No livro "Pra lá de Marrakesh" percebemos a potencialidade em quebrar estereótipos da geografia física africana, e apresentar uma África constituída de população e sociedades plurais. Porém, o livro não menciona em sua narrativa a relação entre o território africano e brasileiro, que se conectaram com a prática de tráfico de homens e mulheres africanos para serem escravizados no Brasil. Com objetivo de lucro econômico, o tráfico escravagista cruzou as histórias de pessoas de diferentes territórios e seus diferentes contextos sociais e culturais. Para manter a prática escravista, foi necessário que os gestores do território brasileiro utilizassem de uma hierarquia social pautada na branquitude como dominante.

E apesar da abolição ter ocorrido em 1888, não foram incluídas medidas governamentais de inserção social/ inserção cidadã, mas sim houve uma manutenção do discurso que coloca todo sujeito não branco num lugar de inferioridade e vulnerabilidade. Simultaneamente, na tentativa de camuflar as disparidades étnicas e sociais, implementa-se a ideia de uma igualdade com objetivo de manter a "harmonia social". Por isso mesmo, "a afirmação de que todos são iguais perante a lei", assume um caráter nitidamente formalista em nossa sociedade. O racismo latino-americano é suficientemente sofisticado para manter negros e índios na condição de segmentos subordinados no interior das classes mais exploradas" (GONZALEZ, 1988, p.73).

Por não abordar essa relação espacial e histórica dos dois territórios, o livro em sua narrativa, não inicia diretamente o debate sobre as questões etnoraciais, tema urgente a ser trazido e trabalhado com seriedade no ambiente escolar, visto que um cidadão que reconhece a escravização, o impedimento secular de acessos à terra, trabalho e escola para negros e indígenas em nosso país, poderá questionar as piadas racistas, assim como as ausências indígenas e negras nos espaços institucionais de poder e de saber. O que demonstra que esse cidadão conseguiu perceber e refletir sobre a forma preconceituosa e desigual que a população não branca é tratada no Brasil. Isso não exclui a possibilidade do professor de levar esse debate para turma, sendo a partir do livro ou não. Cabe ao professor, exercer seu papel como pesquisador, e buscar meios para unir as narrativas do livro, presentes e ausentes, com o conteúdo em sala de aula. O livro não tem objetivo de ser uma manual didático, mas com criatividade pode ser um ponto de partida.

Um exemplo que sugerimos, para além do conteúdo tradicional, é trabalhar palavras de origem africana que estão inseridas no nosso vocabulário e não percebemos, como forma de demonstrar essa relação entre os dois territórios. Outra possibilidade é trabalhar juntamente o livro "Meu avô africano" da autora Carmen Lucia Campos (2010), que aborda especificamente as influências culturais do continente africano no Brasil a partir da narrativa de uma

ParaOnde!?, Porto Alegre, v.14, n.1, p.127-142, 2020.http://seer.ufrgs.br/paraonde 
um família de descendência africana. A leitura é curta e pode ser feita de maneira coletiva em um período de aula e aborda outros conteúdos complementares ao livro "Prá lá de Marrakesh".

A literatura faz um convite para que nós professores utilizemos de seus enredos como uma linguagem pedagógica. São inúmeras as possibilidades de utilizar as narrativas literárias e seus planos de fundos dentro da sala de aula. $O$ papel do professor nesse processo é fundamental, é responsabilidade do professor enxergar seus alunos nas leituras que for propor, analisar as potencialidades e lacunas presentes na história e pesquisar uma forma que una o enredo com o conteúdo de sala de aula.

Além disso, Chimamanda Ngozi Adichie (2018) aborda o perigo de uma história única. A autora cita a importância de conhecer vários pontos de vista de um mesmo lugar, para não se perder na ideia idealizada deste. Ou seja, por vezes os alunos conhecem a ideia de uma África com paisagens encantadoras e pessoas pobres, que necessitam ajuda dos povos brancos colonizadores para se humanizar. Nesta proposta, buscou-se desconstruir estereótipos acerca do continente para desmistificar essa história, e reconstruí-la com olhos mais atentos às diferenças. Além disso, estabelecer a relação da história da África com o Brasil aproxima o aluno desta realidade, que por vezes pode ser a de seus ancestrais. A representatividade que o livro traz para a sala de aula faz esse espaço não ser tão excludente e caracterizado, na maioria das vezes, por autores brancos e homens. Se o aluno consegue identificar-se com um personagem, tanto fisicamente quanto em sua realidade vivida, sente-se representado e percebe como há mais pessoas parecidas com ele. Portanto, essa leitura pode se tornar uma ferramenta essencial na luta antirracista.

\section{Considerações finais}

Como mostrou-se neste texto, a utilização da literatura de forma pedagógica é apoiada e se encontra presente em diferentes áreas do conhecimento como na área da letras, sociologia e geografia. Acreditamos que a partir dessas bases teóricas, o movimento a ser feito é o de construções e aplicações pedagógicas que promovam o ensino interdisciplinar tendo o livro como um meio para estudar as diferentes geografias. A participação do professor como um mediador entre as narrativas literárias e geográficas em sala de aula é essencial para a dinâmica, que se faz presente na relação entre o docente e seus alunos, na hora da escolha de um livro que desperte o interesse e seja adequado para o momento escolar em que os alunos estejam.

Encontram-se, no universo literário, muitas respostas às nossas divagações sobre o mundo, e como também podemos ser ferramentas ativas no processo de transformação dos paradigmas mundiais. A leitura pode ser determinante para a reflexão plena sobre problemáticas que afligem o mundo. Essas leituras nos formam como cidadãos, nos permitem experienciar a vida do outro, e com isso, alimentam a construção de empatia. Trazer isso para o ambiente escolar é proveitoso por isso.

Outra reflexão pensada foi como aguçar a vontade do aluno nas leituras. Se a narrativa do livro for próxima da realidade do aluno, ele pode se interessar, por se identificar com vivências dos personagens, raça e etnia. Por isso, para

ParaOnde!?, Porto Alegre, v.14, n.1, p.127-142, 2020.http://seer.ufrgs.br/paraonde 
cada turma o professor deve adaptar as leituras conforme analisa a realidade dos alunos. Abrir um campo de diálogo com eles, questionando suas vontades de conhecimentos, o tipo de material que gostam de ler, para assim selecionar um livro.

Por fim, a eficácia da proposta de ensino depende da conduta e da sistematização que o docente faz do projeto. A organização, funcionalidade, e aplicabilidade dependem de um trabalho sistematizado, que seja crítico, reflexivo e coeso. Ademais, estar atento as adequações necessárias de cunho cultural, econômico, social e político é essencial para o bom desempenho das atividades. A motivação para leituras não pode ser um projeto isolado de apenas um professor, precisa ser trabalhado de forma interdisciplinar para conseguir êxito. O professor que pesquisa, dialoga com os alunos, buscando caminhos novos para trilharem juntos cumpre seu papel de docente e educador.

\section{Referências}

ADICHIE, Chimamanda Ngozi. O perigo de uma história única. Tradução Julia Romeu. São Paulo: Companhia das Letras, 2018.

ANDRADE, Tiago de Melo. Pra lá de Marrakesh: Rita Pancada na África. Porto Alegre: Edelbra, 2016.

ARROYO, Miguel G. Outros Sujeitos, Outras Pedagogias. Rio de Janeiro: Vozes, 2012.

BARCELLOS, Frederico Roza. Espaço, Lugar e Literatura: o olhar geográfico machadiano sobre a cidade do Rio de Janeiro. Espaço e Cultura, Rio de Janeiro, no 25, p.41-52. Jan./Jun. de 2009.

BRANDÃO, Carlos Rodrigues. A educação como cultura. São Paulo: Brasiliense, 1986.

BRASIL. Base Nacional Curricular Comum (BNCC). Brasília: MEC. 2017. Disponível

em

http://basenacionalcomum.mec.gov.br/images/BNCC_El_EF_110518_versaofin al_site.pdf. Acesso em 08 de outubro de 2020.

BRASIL. Conselho Nacional de Educação. Parecer CNE/CP n. 003/2004 de 10 de

Março de 2004. Diretrizes curriculares nacionais para a educação das relações étnico-raciais e para o ensino de História e Cultura Afrobrasileira e Africana. Diário

Oficial da União, Brasília, DF, 19 maio 2004.

BRASIL. Ministério da Educação. Lei n. 10.639 de 09 de Janeiro de 2003. Altera a Lei no 9.394, de 20 de dezembro de 1996, que estabelece as diretrizes e bases da educação nacional, para incluir no currículo oficial da Rede de Ensino a obrigatoriedade da temática "História e Cultura Afro-Brasileira", e dá outras providências. Diário Oficial da União, Brasília, DF, 10 jan. 2003.

CANDIDO, Antonio. Vários escritos. 6aㅡ ed. Rio De Janeiro: Ouro sobre azul, 2011.

ParaOnde!?, Porto Alegre, v.14, n.1, p.127-142, 2020.http://seer.ufrgs.br/paraonde 
CAMPOS, Carmen Lucia. Meu avô africano. São Paulo: Panda Books, 2010.

CHEVALLARD, Yves. Sobre a teoria da transposição didática: algumas considerações introdutórias. Revista de Educação, Ciências e Matemática, Rio de Janeiro, v.3 no 2. Mai./Ago., 2013.

CLAVAL, Paul. Reflexões sobre a Geografia Cultural no Brasil. Espaço e Cultura, n요, ago. 2013.

COSTELLA R. Z. SCHÄFFER. A Geografia em Projetos Curriculares: Ler o Lugar e Compreender o Mundo. Erechim: Edelbra. 2012.

COSTELLA, Roselane Zordan. O significado da construção do conhecimento geográfico gerado por vivências e por representações espaciais. 2008. 203p. Tese de doutorado, Porto Alegre.

FREIRE, Paulo. Pedagogia da autonomia: saberes necessários à prática educativa. São Paulo: Paz e Terra, 1996.

GONZALEZ, Lélia. A categoria político-cultural de amefricanidade. Tempo Brasileiro, Rio de Janeiro, no․ 92/93. Jan./Jun. 1988.

MARANDOLA JR, Eduardo e OLIVEIRA, Lívia de. Geograficidade e Espacialidade na Literatura. Geografia. Rio Claro, v. 34, n. 3, p. 487-508. Set./Dez. 2009.

MORAES, A. C. R. Geografia, interdisciplinaridade e metodologia. GEOUSP _ Espaço e Tempo (Online), São Paulo, v. 18, no 1, p. 9-39, 2014.

NOGUEIRA, Amélia Regina Batista. Percepção e Representação Gráfica: A "Geograficidade" nos Mapas Mentais dos Comandantes no Amazonas. Tese de doutorado. Departamento de Geografia da USP. São Paulo, 2001.

OLANDA, D. A.; ALMEIDA, M. G. de. A geografia e a literatura: uma reflexão. Geosul. Florianópolis, v. 23, n. 46, p. 7-32, Jul./Dez., 2008.

POMBO, Olga. Epistemologia da Interdisciplinaridade. Revista do Centro de Educação e Letras. Unioeste, Campus Foz do Iguaçu. v.10. no 1. 1ํㅗ. sem. p. 940, 2008.

RAMOS, Graciliano. Vidas Secas. São Paulo: Record, 2003.

REGO, Nelson; MOLL, Jaqueline; AIGNER, Carlos (Org). Saberes e práticas na construção de sujeitos e espaços sociais. Porto Alegre: UFRGS, 2006.

RODRIGUES, Aline de Lima; BUENO, Laura; DALL'AGNESE, Júlia. O ensino de Geografia e a literatura: uma viagem geográfica ao mundo da literatura brasileira. Relatório de Pesquisa. UFRGS, 2020.

SANTOS, Milton. A Natureza do Espaço: Técnica, Razão e Emoção. 3aㅡ ed. São Paulo: Edusp, 2017. 